\title{
MOVIMENTOS SOCIAIS POPULARES EM TEMPOS DE ASCENSÃO DAS NOVAS DIREITAS: a Marcha das Margaridas ${ }^{1}$
}

\author{
Marco Antonio Teixeira *
}

\begin{abstract}
O artigo analisa a Marcha das Margaridas, uma mobilização feminista realizada no Brasil sob a liderança das mulheres do campo, da floresta e das águas, nos anos de 2015 e 2019, considerado o tempo de ascensão das novas direitas. A Marcha é organizada pelas mulheres do Movimento Sindical de Trabalhadores e Trabalhadoras Rurais, em aliança com outros movimentos sociais, centrais sindicais e organizações internacionais. Adota-se uma abordagem teórica que considera a atuação dos movimentos sociais por meio dos conceitos de ações de reprodução social e formas de ação coletivas. Isso significa analisar a Marcha para além de suas expressões mais visíveis - uma grande marcha na cidade de Brasília e as negociações com agentes estatais (formas de ação coletiva). A mobilização envolve também um longo processo de organização, formação e política de alianças com outros atores sociais (ações de reprodução social). Argumenta-se que analisá-las de maneira interdependente e vis-à-vis à estrutura de oportunidades políticas no tempo de ascensão das novas direitas aumenta a capacidade de compreensão de como movimentos sociais populares atuaram considerando o novo contexto.

Palavras-chave: Movimentos Sociais. Novas Direitas. Ações Coletivas. Ações de Reprodução Social. Marcha das Margaridas.
\end{abstract}

\section{INTRODUÇÃO}

No Brasil, as manifestações de junho de 2013 têm sido consideradas como um ponto de inflexão a partir do qual as novas direitas ganharam força (Abreu; Allegretti, 2016; Almeida, 2019; Bringel, 2020). Depois disso, uma série de eventos contribuiu para à ascensão das novas direitas, tais como: a operação Lava Jato, ${ }^{2}$ um conjunto de manifestações nacionais, iniciadas em março de 2015, que conclamaram a deposição da presidenta Dilma Rousseff; o impeachment que destituiu a ex-presidenta do

\footnotetext{
* Instituto de Estudos Latino-americanos (LAI) na Freie Universität Berlin (FU Berlin), Boltzmannstraße 1. 14195. Berlim - Alemanha. marco.teixeira@fu-berlin.de http://orcid.org/0000-0001-5794-4289

${ }^{1}$ Agradeço à leitura e comentários dos pareceristas anônimos, da editora da revista, a Professora Iracema Brandão Guimarães, e de Everton Picolotto, Simone Gomes, Eryka Galindo e Renata Motta nas versões preliminares deste artigo. A responsabilidade pelo conteúdo e suas falhas é minha. A pesquisa é financiada pelo Ministério Federal de Educação e Pesquisa da Alemanha (BMBF).

${ }^{2}$ Refere-se a uma das maiores investigações legais sobre corrupção no Brasil, iniciada em março de 2014. A operacão trouxe à tona um conjunto de conexões ilegais estabelecidas entre o mundo da política (partidos e políticos), o mundo econômico (empresas) e a administração pública (funcionários do Estado). Revelações recentes comprovam o caráter conspiratório da operação para retirar Lula das eleições de 2018 (Miguel, 2019b).
}

poder e levou o então vice-presidente Michel Temer ao cargo mais alto do executivo nacional, em 2016; a eleição de Jair Bolsonaro para a presidência da república, em 2018 (Abreu; Allegretti, 2016; Almeida, 2019; Bringel, 2020; Santos; Tanscheit, 2019). Com maior ou menor clareza conceitual, o termo "novas direitas"3 tem sido utilizado no Brasil em referência a um fenômeno multifacetado e a grupos heterogêneos com princípios e valores conservadores diversos, mas que têm como traço comum o antipetismo (anti Partido dos Trabalhadores - PT), e que ganharam força política nacional nos últimos anos. Para autores como Abreu e Allegretti (2016), a ascensão destes grupos está associada ao domínio das redes sociais e ao comportamento político violento que assumiram nessas redes.

Porém, este fenômeno político tem raízes mais profundas. Bringel (2020) argumenta

${ }^{3}$ Algumas das outras expressões utilizadas para caracterizar este fenômeno são "direitas", "onda conservadora" e "neoconservadorismo" (Solano, 2018; Abranches, 2019). Adotei o termo "novas direitas" para me referir a um contexto socioeconômico e político marcado pela força política destes grupos sociais, que se diferencia de um contexto anterior, marcado, entre outros fatores, pela força política de governos populares na América Latina (Pereira da Silva, 2014), chamado no Brasil de ciclo progressista (Bringel, 2020). 
que há três chaves históricas e políticas para entendê-lo: o fim do ciclo democratizante, conhecido como Nova República, iniciado no final dos anos 1970 com a contestação da ditadura; o fim do ciclo progressista, iniciado em 2002 com a vitória presidencial de Lula e terminado com a destituição de Rousseff; os protestos de junho de 2013 e seus desdobramentos posteriores. $\mathrm{O}$ autor sugere que o crescimento das novas direitas tem uma multidimensionalidade de espaços e frentes de atuação que se articulam, sobrepõem e coexistem: a ação institucional, a disputa cultural/territorial e os protestos de rua. Com isso, conecta dimensões societais e institucionais do que ele denomina direitização no país (Bringel, 2020).

Em relação à disputa institucional, Bringel destaca a conjugação de partidos mais tradicionais de direita com outros criados nos últimos anos, como o Partido Novo, em 2011, construindo assim uma nova roupagem para as direitas, em tempos de descrédito dos partidos tradicionais. Estas coalizões encontraram no antipetismo e na agenda anticorrupção, acionada de forma seletiva, um ponto comum, embora outras afinidades estivessem em jogo, como a agenda econômica. Para Bringel, o "bolsonarismo" conseguiu capitalizar esta conjunção de forças a seu favor nos anos mais recentes. E a disputa cultural/territorial se refere à ancoragem socioespacial, subjetiva e cultural-midiática das novas direitas. Bringel (2020) ন̃ realça a importância da religião - o novo penN tecostalismo - nos territórios e nas redes para a expansão das novas direitas, fator também \& ressaltado por outros autores, como AlmeiA da (2019), para quem grupos evangélicos são constituintes desta onda conservadora.

Em relação à dimensão dos protestos de ruas, Bringel (2020) analisa que as novas direitas ocuparam espaços de disputa comumente associados às esquerdas, almejando uma forma de legitimação política frente à mídia, à sociedade e aos seus antagonistas e uma maneira de mostrar capacidade de mobilização. Os protestos de rua foram protagonizados por jovens liberais e conservadores, expressando uma renovação geracional nas direitas que conhece o funcionamento das redes sociais e sabe potencializá-la ${ }^{4}$ (Bringel, 2020). As manifestações de 2015 e 2016 a favor do impeachment da presidenta Dilma e antipetistas têm sido consideradas marcos da força das novas direitas nas ruas (Abreu; Allegretti, 2016) e a base para a ascensão de Jair Bolsonaro (Solano, 2019).

Contudo, essa ascensão, ocorrida no Brasil nos últimos anos, não ocorreu sem conflitos e resistências. Em relação à ação institucional, embora se tenha construído a imagem de polarização política que situa o PT como o inimigo das novas direitas, outras forças políticas também se contrapuseram a elas, como o Partido Socialista Brasileiro (PSB), o Partido Democrático Trabalhista (PDT), o Partido Comunista do Brasil (PCdoB) e o Partido Socialismo e Liberdade (PSOL). Entre eles, o debate sobre a potencial coalizão de uma frente ampla de centro-esquerda para tentar reverter as perdas eleitorais recentes está na ordem do dia (Boulos..., 2021). Em relação à disputa cultural/territorial, há um diagnóstico compartilhado por forças do campo da esquerda, sobre a necessidade de se retomar o trabalho de base, embora esta atividade não tenha sido abandonada completamente por muitos atores sociais (João..., 2018). Por fim, diversos protestos de rua buscaram visibilizar as oposições contra as novas direitas e suas ideias políticas, entre os quais se destacam os atos contra o impeachment da Dilma Rousseff; protestos conhecidos como "Fora Temer", iniciados logo após o impeachment e que pediam a saída do novo presidente em exercício; e as mobilizações do \#EleNão, ocorridas em 29 de setembro de 2018, lideradas por mulheres e organizadas por redes sociais, principalmente no grupo "Mulheres Unidas Contra Bolsonaro" no Facebook.

\footnotetext{
4 Miguel (2019a) destacou que a disseminação de fake news (notícias falsas) por sistemas alternativos de comunicação é um dos elementos que compõe o cenário de crise da democracia. Este recurso foi utilizado de maneira deliberada por Jair Bolsonaro, na eleição presidencial de 2018, sobretudo por meio do WhatsApp e YouTube. Neste processo, o jornalismo profissional foi marginalizado, na medida em que o líder político passou a se relacionar de forma imediata com seus "seguidores".
} 
Estudos recentes sobre as mobilizações no Brasil têm se concentrado, com algumas exceções, nos protestos de junho de 2013 (Singer, 2013; Bringel; Pleyers, 2015; Alonso; Mische, 2017), nas mobilizações de 2015 e 2016 (Ortellado; Solano, 2016; Telles, 2016), ou interpretações mais gerais sobre as tendências dos protestos nos anos mais recentes (Alonso, 2017; Tatagiba; Galvão, 2019). Contudo, outras mobilizações e movimentos sociais têm tido pouco espaço nas interpretações recentes sobre o papel dos movimentos sociais no novo contexto, como é o caso do Movimento dos Trabalhadores Rurais Sem-Terra (MST), foco de estudos, sobretudo, nos anos 1990. Além daqueles protestos mais imediatamente ligados à conjuntura de polarização política após as Jornadas de Junho de 2013, há que se investigar como os movimentos sociais populares mais históricos adaptam sua resistência à nova conjuntura de ascensão das novas direitas. Este artigo contribui para esta agenda incipiente de pesquisa, a partir da análise da Marcha das Margaridas, conhecida como uma mobilização de mulheres do campo, da floresta e das águas que, desde 2000, caminha nas ruas de Brasília para lutar por reconhecimento, direitos e políticas públicas.

A Marcha das Margaridas é coordenada pela Secretaria de Mulheres da Confederação Nacional dos Trabalhadores Rurais Agricultores e Agricultoras Familiares (Contag), que é a mais alta instância de representação do Movimento Sindical de Trabalhadores e Trabalhadoras Rurais (MSTTR), sendo construída em parceria com movimentos sociais, feministas, de mulheres, centrais sindicais e organizações internacionais. Deve-se acrescentar que foram realizadas até o momento seis ações nacionais de rua da Marcha das Margaridas ao longo dos mais de 20 anos de sua existência. ${ }^{5}$ As duas

${ }^{5} \mathrm{O}$ nome da Marcha é um tributo a Margarida Maria Alves, líder sindical paraibana assassinada por sua luta pelos direitos da classe trabalhadora, em 1983. A Marcha é parte de uma trajetória mais ampla de organização política das mulheres, sobretudo as sindicalistas rurais, desde pelo menos os anos 1980. (Pimenta, 2019; Aguiar, 2015; Teixeira, 2018; Moreira, 2019; Teixeira; Motta, 2020). últimas aconteceram em momentos cruciais de ascensão das novas direitas. Em agosto de 2015, estava em discussão a aceitação do processo de impeachment da presidenta Dilma Rousseff pelo então presidente da Câmara dos Deputados, Eduardo Cunha (Movimento Democrático Brasileiro). Em agosto de 2019, oito meses após o início do governo Bolsonaro, a Marcha foi o maior protesto de rua no país naquele ano e reafirmou como uma das suas características, conforme consta em um dos documentos políticos naquele ano, a "resistência e enfrentamento ao avanço da agenda antidemocrática, conservadora e privatista" (Contag, 2019b, p. 15). De acordo com a comissão organizadora, é a maior ação de mulheres do campo da América Latina, mobilizando entre 20 e 100 mil mulheres em Brasília, capital do país, conforme cada edição.

Analisar uma mobilização de mulheres é particularmente importante por pelo menos dois motivos. Primeiro, devido ao crescimento deste tipo de mobilização na América Latina nos anos mais recentes. No Brasil, citam-se os atos do 8 de março, Dia Internacional da $\mathrm{Mu}$ lher; a campanha \#MulheresContraCunha, que se opôs contra o Projeto de Lei 5.069, de autoria do então presidente da Câmara Eduardo Cunha, que dificultava o atendimento às mulheres vítimas de violência sexual; as mobilizações do \#EleNão, já mencionadas. Segundo, porque para algumas autoras, como Pinheiro-Machado (2019), a ascensão do neoconservadorismo, para utilizar a expressão da autora, deve ser entendida, em parte como reação ao crescimento do feminismo, do antirracismo e das lutas de grupos LGBTQI+.

Este artigo se divide em três partes. $\mathrm{Na}$ primeira, apresento a abordagem teórica, com destaque para os conceitos de ações de reprodução social, de formas de ação coletiva e oportunidades políticas. Na segunda e na terceira, analiso, respectivamente, as ações de reprodução social e as formas de ação coletiva da Marcha das Margaridas no contexto de ascensão das novas direitas. Por fim, apresento 
as considerações finais do artigo. Em relação à metodologia, utilizei documentos sobre a Marcha; entrevistas com as coordenadoras nacionais e parceiras realizadas em 2015 (Teixeira, 2018), e a partir de 2019; dados provenientes de um survey realizado com as ativistas durante a Marcha de 2019, ambas no contexto do Grupo de Pesquisa Alimento para Justiça; ${ }^{6}$ e observação participante das Marchas de 2015 e 2019.

\section{FORMAS DE AÇÃO COLETIVA, AÇÕES DE REPRODUÇÃO SOCIAL E ESTRUTURA DE OPORTUNIDA- DES POLÍTICAS}

Há duas abordagens principais sobre a atuação dos movimentos sociais. A primeira se relaciona mais à problemática da ação coletiva e tem entre as suas principais referências a teoria do processo político (Tilly, 1978; Tarrow, 1989; McAdam; 1999) e a teoria da mobilização de recursos (McCarthy; Zald, 1977). A segunda encontra na teoria dos Novos Movimentos Sociais seus principais expoentes (Touraine, 1984; Melucci, 2001).

Um conceito central no debate sobre ação coletiva é o repertório de confronto (Tilly, 1978), cuja característica central é analisar ações contenciosas em detrimento daquelas imbuídas de consenso (Tilly, 1978). Neste trabalho, utilizo o conceito de formas de ação coনิ letiva, que se refere às maneiras pelas quais os సे movimentos sociais atuam publicamente para alcançar determinados objetivos, tais como ¿ passeatas, greves e atuações em espaços parti今 cipativos de formulação, monitoramento e ava¿. liação de políticas públicas (Teixeira, 2018). ஓं Elas se diferenciam do repertório de confronto,

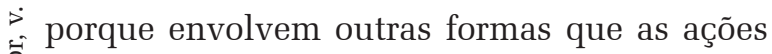
dos movimentos sociais podem assumir, e que

ב ${ }^{6}$ O survey foi realizado durante a Marcha das Margaridas de 2019, pelo Grupo de Pesquisa Alimento para Justiça. Utilizo aqui os dados colhidos na modalidade face a face com as participantes mulheres da Marcha. Um total de 458 questionários foram respondidos, em uma amostragem probabilística. não se estruturam apenas por conflitos. ${ }^{7}$ Neste sentido, o que estrutura a ação coletiva é a relação social, mais do que os conflitos. ${ }^{8}$

Dois aspectos são centrais na concepção de formas de ação coletiva: a diversidade das formas que a ação pode assumir e a multiplicidade das motivações que fundamentam o desencadeamento da ação. Os trabalhos de Sigaud (1986), Thompson (1998), Scott (2002), Palmeira (2009) e Teixeira (2015) foram as inspirações para pensar na diversidade das formas de ação coletiva para além das suas formas mais conhecidas, tais como rebeliões, greves e protestos. $\mathrm{O}$ ponto em comum a estes autores consiste em analisar ações coletivas, usualmente não tratadas como tal, consideradas prosaicas, cotidianas, realizadas em períodos de aparente interregno das lutas sociais, mas que eram marcadas por enfrentamentos. Enquanto Thompson (1998) cunhou a expressão "economia moral dos pobres" para se referir aos motivos morais e não apenas econômicos que motivavam a ação coletiva, Honneth (2003) reforçou a concepção de que os estudos sobre ação coletiva não têm como ponto de partida apenas interesses pragmáticos e racionais, mas também sentimentos morais de injustiça.

A principal inspiração para o desenvolvimento do conceito de ações de reprodução social foi a crítica feminista ao modelo de explicação da reprodução social do trabalho em Karl Marx. Federici (2004) argumentou haver uma lacuna nas análises de Marx sobre as transformações que o capitalismo introduziu

${ }^{7}$ Outro problema nas perspectivas que enfatizam os conflitos nos estudos das ações coletivas é que elas tendem a igualar ação coletiva às grandes mobilizações (Teixeira, 2018), perdendo de vista que os atores dedicam tempo e recursos significativos para desenvolver e sustentar outras formas de ação nas quais o conflito não é uma característica constitutiva, conforme sugere Silva (2010).

8 Também inspiradas nas formulações de Tilly, porém, aprofundando seu desenvolvimento conceitual, Abers, Serafim e Tatagiba (2014) desenvolveram o conceito de repertório de interação entre Estado e sociedade civil para analisar relações que envolvem não só dinâmicas contenciosas, mas também dinâmicas colaborativas entre atores no Estado e na sociedade; enquanto Rossi (2016) propôs os conceitos de "repertórios de estratégias" e "estoque de legados" para abarcar a diversidade de práticas que os atores coletivos desenvolvem historicamente a partir do estudo dos movimentos piqueteros argentinos. 
na reprodução da força de trabalho e na posição social das mulheres. Para a autora, no novo sistema que estava sendo criado, as atividades das mulheres foram definidas como não trabalho, como um recurso natural disponível para todos. E isso forneceu as bases necessárias para a fixação delas no trabalho reprodutivo e para utilizá-las como trabalho mal remunerado na indústria artesanal doméstica. "No entanto, a importância econômica da reprodução da força de trabalho realizada no âmbito doméstico e sua função na acumulação do capital se tornaram invisíveis, sendo mistificada como uma vocação natural e sendo designada como "trabalho de mulheres" (Federici, 2004, p. 132-133). Inspirado na reflexão de Federici e em outros trabalhos que analisam as atividades entendidas como não produtivas exercidas pelas trabalhadoras rurais e que são fundamentais para a reprodução do campesinato/agricultura familiar/modo de vida rural (Medeiros; Neves, 2013; Hora; Macedo; Rezende, 2015), propus o conceito de ação de reprodução social para identificar as ações dos movimentos sociais que não são públicas e visíveis como os atos de protesto, porém são necessárias para a construção social destes atores coletivos (Teixeira, 2018). As ações de reprodução social são, portanto, atividades que criam as condições necessárias para o desenvolvimento das ações coletivas e para a própria existência e perenidade dos movimentos sociais, tais como as políticas de alianças com outros movimentos sociais, reuniões e formação política (Teixeira, 2018).

Ações de reprodução social e formas de ação coletiva são dimensões interdependentes que precisam ser analisadas dessa forma para que se entenda a atuação dos movimentos sociais de uma maneira mais holística. Esta abordagem evita interpretações que focalizam comumente apenas a dimensão pública da atuação dos movimentos sociais e, por isso, concluem que os movimentos sociais estão desmobilizados quando não estão nas ruas (Teixeira, 2018; Gomes, 2020; Medeiros, 2020). Para entender o contexto no qual a Marcha atua, recor- ro também ao conceito de oportunidades políticas, que em linhas gerais se refere à relação entre um grupo e o mundo ao seu redor (Tilly, 1978; Tarrow, 2009). O termo busca apreender os incentivos e os constrangimentos políticos que facilitam ou limitam as possibilidades de ação. De acordo com Tarrow (2009), o conceito não deve ser entendido como um modelo invariável que produz, inevitavelmente, movimentos sociais, mas como um conjunto de indícios de quando surgirá um confronto político.

A seguir, iniciarei a análise da atuação da Marcha das Margaridas pelo estudo das suas ações de reprodução social por entender que elas criam condições para a existência e construção das ações coletivas. Farei isso tomando por base as oportunidades políticas que marcaram as mobilizações de 2015 e 2019 da Marcha, ressaltando as interpretações do contexto produzidas pelos sujeitos políticos.

\section{AÇÕES DE REPRODUÇÃO SOCIAL DA MARCHA DAS MARGARIDAS}

A Marcha das Margaridas não é um protesto pontual, mas uma mobilização que envolve um processo de construção política permanente. O encontro dos participantes em Brasília, para marchar e interpelar o Estado, é a culminação de um longo processo que envolve ações de reprodução social, como uma política de alianças com outros atores, organização, mobilização e formação. No trecho abaixo, Mazé Morais, coordenadora nacional da Marcha em 2019, destaca a importância dessas ações:

a Marcha não é só aquele ato aqui, a gente entende que é um processo de formação, de construção, de mobilização, que isso é que é o forte da Marcha, é esse processo. Os dois dias aqui, ele é o marco de todo o coroamento de todo o processo, mas aquele processo que fica na base, de construção, de formação, isso é o que deixa mesmo a marca lá na base. ${ }^{9}$

${ }^{9}$ Entrevista com Mazé Morais realizada pelo autor em 5 de março de 2020 
O processo de organização da Marcha se inicia muito antes da realização do ato nacional. A política de alianças (Aguiar, 2015; Motta; Teixeira, 2021; Teixeira; Motta, 2020), presente desde sua criação, no ano 2000 , fortalece o poder político da mobilização e promove a troca de experiências e aprendizagem entre ativistas e suas organizações. A coordenação geral da Marcha é feita pela Comissão Nacional de Mulheres Trabalhadoras Rurais, composta pela Secretária de Mulheres da Contag e pelas Secretarias de Mulheres das 27 federações estaduais filiadas à Confederação. Conta também com uma coordenação ampliada, que inclui outros movimentos sindicais, sociais, feministas, de mulheres e organizações nacionais e internacionais. Porém, a política de alianças sofreu modificações frente ao novo contexto de ascensão das novas direitas.

Focalizando principalmente a investigação das alianças entre organizações, é possível observar o crescimento das coalizões em 2015 e 2019 devido às ameaças políticas naquele momento. A iminência da abertura do processo de impeachment contra a então presidenta Dilma Rousseff estava sendo orquestrada no contexto da mobilização de 2015 e veio a se concretizar no ano seguinte. Relatos das organizadoras da Marcha destacam que muitas(os) ativistas e movimentos sociais aderiram ao protesto de rua, realizado pelas Margaridas, por entenderem que aquela manifestação era নิ também um espaço de luta contra a ameaça $\overbrace{\infty}^{\circ}$ dos retrocessos democráticos que ameaçavam $\stackrel{\circ}{\circ}$ o país com um processo de impeachment, que ¿े tinha sua legitimidade questionada por muitos $\neg$ movimentos sociais. Esta pauta fez parte da ¿. agenda política da Marcha das Margaridas na में sua edição de 2015.

Mas o cenário em 2019 já era diferente. A eleição de Jair Bolsonaro para a presidência da república foi entendida como um retrocesso democrático por muitos movimentos sociais de esquerda, que passaram a ser mais intensamente criminalizados, sobretudo, nas falas do presidente e seus apoiadores. ${ }^{10} \mathrm{O}$ contexto de ameaças impulsionou ativistas a falarem sobre a importância de estabelecerem alianças para se contrapor à onda conservadora, às novas direitas e aos retrocessos democráticos.

O resultado disso foi não só a adesão de diversos ativistas nas ruas, estabelecendo vínculos mais contingentes, mas também na comissão organizadora da Marcha. O número de entidades parceiras da Marcha subiu de 12, em 2015, para 16, em 2019. ${ }^{11}$ A adesão da Coordenação Nacional de Articulação das Comunidades Negras Rurais Quilombolas (Conaq) e do Movimento de Mulheres Camponesas (MMC), ligados à Via Campesina, foi uma das maiores novidades da Marcha de 2019, porque a Via é uma rede transnacional de movimentos camponeses e que, no Brasil, reúne diversos movimentos rurais em uma corrente política diferente da Contag. ${ }^{12}$ Para uma das li-

${ }^{10}$ Em seu Twitter, no dia 5 de outubro de 2020, o presidente Jair Bolsonaro incitou sua militância contra o MST por meio de um vídeo em que exibe supostos membros de um movimento social que aparecem em uma propriedade rural proferindo palavras de ordem ligadas à luta pela reforma agrária. Ao final da publicação, o presidente registra a frase: "Tenho minha opinião, qual a sua?". A postagem foi suficiente para que, rapidamente, dezenas de seguidores começassem a responder se referindo ao MST como “terroristas” (Longo, 2020).

11 As parceiras que compuseram a comissão de organização ampliada da Marcha tanto em 2015 quanto em 2019 foram: Articulação de Mulheres Brasileiras (AMB), Central das Trabalhadoras e dos Trabalhadores do Brasil (CTB), Central Única dos Trabalhadores (CUT), Conselho Nacional das Populações Extrativistas (CNS), Coordenação das Organizações de Agricultores Familiares do Mercosul (Coprofam), Grupo de Trabalho (GT) Mulheres da Articulação Nacional de Agroecologia (ANA), Marcha Mundial das Mulheres (MMM), Movimento Articulado de Mulheres da Amazônia (Mama), Movimento de Mulheres Trabalhadoras Rurais do Nordeste (MMTR-NE), Movimento Interestadual das Quebradeiras de Coco Babaçu (MIQCB), União Brasileira de Mulheres (UBM) e União Nacional das Cooperativas da Agricultura Familiar e Economia Solidária (Unicafes). Vale destacar que há assimetrias de envolvimento das diferentes organizações no processo de organização da Marcha, aspecto que não tratarei aqui por não ser o foco do artigo.

${ }^{12}$ A tensão entre a Contag e a Coordenadoria Latino-Americana de Organizações do Campo (Cloc), que depois se tornou o braço regional da Via Campesina, sobre a atuação no âmbito do Mercado Comum do Sul (Mercosul) nos anos 2000, principalmente em relação ao tema comercial, foi um elemento que levou ao afastamento entre os movimentos (Carvalho, 2021). A Contag passou a se articular transnacionalmente com outros movimentos sindicais da região por meio da Confederação de Organizações de Produtores Familiares do Mercosul (Coprofam) (Luiz; Carvalho; Teixeira, 2020). Os movimentos ligados a Via Campesina e a Contag, assim como outras organizações, se reúnem no Campo Unitário, que é um espaço de articulação de entidades do campo que se reúnem para articular pautas e fortalecer ações em conjunto. 
deranças do MMC, o que motivou esta adesão foi a compreensão de que era importante unir forças em um momento conjuntural marcado por retrocessos democráticos. ${ }^{13}$ Também merecem destaque a adesão da Comissão Nacional de Fortalecimento das Reservas Extrativistas e dos Povos Extrativistas Costeiros Marinhos (Confrem), trazendo, sobretudo, a representação das mulheres das águas para a comissão organizadora da Marcha, e a Confederação Nacional dos Trabalhadores Assalariados e Assalariadas Rurais (Contar), entidade criada em outubro de 2015 a partir da dissociação sindical da Contag. Outra novidade em 2019 foi a aliança da Marcha das Margaridas com a Marcha das Mulheres Indígenas, que aconteceu pela primeira vez e reuniu 3 mil mulheres em Brasília entre 9 e 14 de agosto em defesa de seus territórios e seus direitos. A aliança entre as Margaridas e as Indígenas teve como atos simbólicos diversos eventos: uma sessão solene na Câmara dos Deputados em homenagem às duas Marchas; na abertura política da Marcha das Margaridas; e nos protestos de rua - as Margaridas se uniram às mulheres indígenas e vice-versa. Estas alianças não acontecem sem tensões e conflitos. As parcerias e sentidos construídos são aqueles possíveis diante da diversidade e, inclusive, reconhecendo a diferença como elemento que possibilita as coalizões (Motta; Teixeira, 2021).

A mobilização para a Marcha implica uma construção política que envolve suas participantes em diversos momentos, aspecto considerado pelas lideranças como um diferencial e um fator para explicar a alta adesão das ativistas ao protesto em Brasília. Mobilização, organização e formação política são ações simultâneas e que se retroalimentam. O lócus principal de mobilização é o território e município, nas áreas rurais e urbanas. Nas últimas edições, o lançamento da Marcha aconteceu um ano antes aos dias de protestos públicos e incluiu reuniões de planejamento da comis-

${ }^{13}$ Entrevista com Michela Calaça realizada pelo autor em 9 de agosto de 2020 . são organizadora, desta com as parceiras, encontros estaduais e regionais de planejamento e mobilização, atividades de arrecadação de fundos, entre outras. Um exemplo das atividades de organização e mobilização é a arrecadação de dinheiro para financiar a Marcha e a viagem das ativistas para Brasília. Os recursos geralmente vêm dos fundos das próprias organizações, de convênios com o Estado ou organizações da sociedade civil, ou de arrecadação promovida pelas ativistas. São necessários para viabilizar infraestrutura, alimentação, divulgação, comunicação e atividades culturais. De acordo com Raimunda Damascena, coordenadora nacional da mobilização em 2000 e 2003, a Marcha teve pouco apoio financeiro de convênios com o Estado no começo, sobretudo em 2000, quando o presidente da república era Fernando Henrique Cardoso, do Partido da Social Democracia Brasileira (PSDB), cuja política não se alinhava aos interesses de muitos movimentos sociais de esquerda. ${ }^{14}$ Nas edições seguintes, houve maior abertura dos agentes do poder executivo nacional, nas gestões do PT, para dialogar com os movimentos sociais de esquerda, e os convênios aumentaram.

Como já apontado, a ascensão das novas direitas agravou a criminalização dos movimentos sociais de esquerda. E com a eleição de Bolsonaro, o canal de construção de convênios entre Estado e movimentos populares se fechou, trazendo implicações para o financiamento da Marcha. Para além das tradicionais festas, rifas e venda de produtos, realizadas em todo o país, a comissão organizadora fez uma campanha de financiamento coletivo pela internet. ${ }^{15}$ Ao mesmo tempo em que pode ser entendida como uma resposta ao contexto de restrições políticas, o financiamento pela internet pode ser visto também como uma estratégia das Margaridas que dialoga com um contexto de oportunidades políticas, caracterizado pelo

${ }^{14}$ Entrevista com Raimunda Damascena realizada pelo autor em 22 de outubro de 2015.

15 A campanha ocorreu por meio do website Benfeitoria. Disponível em: https://benfeitoria.com/marchadasmargaridas. Acesso em: 20 mar. 2021. 
crescimento do uso da internet e redes sociais para atividades políticas, tema que faz parte da agenda de estudos sobre movimentos sociais há algum tempo (Alcântara, 2015). Contudo, a campanha de financiamento coletivo não tinha só por objetivo arrecadar recursos. De acordo com as organizadoras, buscava também divulgar a Marcha para a sociedade, atingindo um público mais amplo do que comumente faz. Esta ação ganha sentido em um escopo mais amplo do significado que a Marcha assumiu em 2019, quando a comissão organizadora decidiu estabelecer diálogos com a sociedade sobre as demandas das Margaridas, seu projeto político e o contexto naquele momento, mais do que entregar demandas e negociar com agentes do Estado, aspecto mais comum nos anos anteriores, sobretudo entre 2003 e 2005. A meta da campanha era arrecadar $\mathrm{R} \$ 80.000,00$, e o total obtido foi de R $\$ 131.457,00$.

Não foi incomum ouvir de muitas pessoas envolvidas na organização do evento que esta tinha sido a primeira vez que a Marcha não contava com nenhum tipo de financiamento externo. Em geral, a enunciação disto conclamava para o caráter mais orgânico e popular da mobilização, feito pelas próprias ativistas sem apoio externo. No survey realizado com as ativistas em 2019, 47,6\% das participantes da Marcha afirmaram terem se envolvido em atividades de arrecadação de fundos, número expressivo considerando o universo de particiస్రి pantes. Outra ação de reprodução social são as ๙ atividades de formação política, sobre a qual Raimunda Damascena comenta:

[...] o Grito da Terra [mobilização organizada anualmente pelo MSTTR desde 1994] só tem palavras de ordem, mas na Marcha, as mulheres saem cantando, de lá até aqui. Elas saem cantando. Quando elas não cantam, elas fazem seminários lá dentro, daqueles ônibus, elas fazem oficinas. A Marcha de 2003, elas fizeram seminários de auto-formação para não ser só aquele lugar de jogar cartas, de tocar não sei o que. 'Não. Vamos conversar sobre essa nossa proposta política. O que é o feminismo; o que é o machismo; por que é que nós estamos aqui, companheiras? Por que nós estamos juntas? O que isso nos traz? Que força é essa, que nos convoca a todas nós, para construir um mundo possível, para nós e para o mundo?'16

Pelo trecho acima é possível destacar dois aspectos da formação política, os quais na linguagem política do MSTTR se traduzem nos termos formação programada e formação na ação, ambos espaços de reflexão política sobre os desafios da luta sindical (Contag, 2008). A primeira acontece, por exemplo, por meio de cursos, seminários, oficinas, enquanto a segunda é parte da prática política cotidiana, parte constitutiva da organização e mobilização das ativistas no decorrer do processo de construção da Marcha e da participação das ativistas. A preocupação com a formação ocupa um lugar central na estratégia de organização da mobilização. Em diversas reuniões, tanto em 2015 quanto em 2019, presenciei debates entre as organizadoras da Marcha sobre a importância de garantir que as ativistas que cheguem à mobilização de rua tenham debatido os eixos temáticos que orientam a mobilização.

As atividades de formação política cumprem um duplo papel: além da formação política de ativistas, serve como meio para a construção da agenda política da Marcha. A cada edição, as Margaridas elaboram documentos políticos que apresentam suas visões de mundo e demandas políticas. São orientados pelo lema e pelos eixos políticos de cada edição. Conforme consta na plataforma política da Marcha, em 2019, este documento é "fruto de um amplo processo de discussões e debates, realizado em âmbito municipal, estadual e nacional, a sua construção envolveu trabalhadoras do campo, da floresta e das águas, desde as suas comunidades, dos seus locais de atuação, às quais se somaram trabalhadoras urbanas, ativistas e lideranças" (Contag, 2019a, p. 2).

O foco dos temas debatidos varia conforme os objetivos da mobilização a cada ano e de acordo com o contexto político. Tomando como ponto de referência para debate os le-

${ }^{16}$ Entrevista com Raimunda Damascena realizada pelo autor em 22 de outubro de 2015. 
mas da Marcha, em 2015 o foco foi "Margaridas seguem em Marcha por Desenvolvimento Sustentável com Democracia, Justiça, Autonomia, Igualdade e Liberdade”. Pela primeira vez, o tema democracia é incorporado no lema central da Marcha, em uma clara resposta à ameaça de retrocessos democráticos existentes naquele momento e que se confirmou após a Marcha com o impeachment contra a presidenta Rousseff. Com a mudança no cenário político marcado pela eleição de Bolsonaro, a comissão organizadora da Marcha em 2019 escolheu como lema "Margaridas na luta por um Brasil com soberania popular, democracia, justiça, igualdade e livre de violência”. No novo lema, as Margaridas reafirmaram o tema da democracia, na relação com a soberania popular, e evidenciaram o enfrentamento à violência, presente nos lemas da Marcha nas três primeiras edições, e que voltou a ter centralidade em face a um contexto de crescimento da violência contra mulheres e povos do campo, da floresta e das águas, que ganha força com a criminalização dos movimentos sociais.

Também é possível avaliar o envolvimento das participantes nas atividades de formação. 61,1\% das ativistas da Marcha 2019 afirmaram terem participado de cursos, oficinas ou reuniões de debate político preparatórios; e 49,1\% disseram ter tido a oportunidade de discutir os Cadernos de Debate da Marcha com antecedência. Esses dados são um indício do intenso envolvimento das participantes no processo de construção da Marcha, sobretudo, considerando que o survey é representativo do universo de participantes que aderem à mobilização de rua em Brasília, muitos de forma espontânea, enquanto a formação política é voltada sobretudo para um público com algum nível de engajamento político, e pode envolver mais ativistas do que aquelas que têm oportunidade de ir para a Brasília, uma vez que as atividades são organizadas principalmente pelo MSTTR.

O estudo do modo como movimentos e mobilizações sociais populares têm atuado em tempos de ascensão das novas direitas é impor- tante para entender como as resistências têm se forjado para além dos protestos pontuais. Analisar as ações de reprodução social da Marcha das Margaridas é uma maneira profícua de compreender como transformações se operaram no processo de construção da mobilização, dimensão nem sempre visível e pouco abordada nos estudos das resistências de movimentos sociais às novas direitas. A análise deste caso revelou que o novo contexto não afastou as Margaridas do trabalho político que desenvolviam, mas implicou em transformações nas suas ações de reprodução social, produzindo, por exemplo: a ampliação das alianças e mobilização com organizações de mulheres e feministas; a reinvenção de estratégias organizativas, com a ampliação do apoio à Marcha por meio de campanhas na internet; e reorientações do debate político e o foco da formação política das ativistas. Estas ações garantem não só a perenidade da Marcha, mas são também condições para as ações coletivas e criam resistências, tema que aprofundarei na próxima seção.

\section{FORMAS DE AÇÕES COLETIVAS: margaridas nas ruas e nos gabinetes}

As marchas ou protestos de rua e a interpelação do Estado estão entre as principais formas de ação coletiva empregadas pelas ativistas da Marcha das Margaridas. ${ }^{17}$ Essas duas formas de ação coletiva estão inter-relacionadas e se complementam. O poder de negociação das representantes da Marcha com agentes do Estado está em grande medida relacionado à capacidade de mobilização da Marcha nas ruas; assim como há correlações entre o engajamento de ativistas e a crença de que a Marcha é capaz de lhes representar e obter conquistas de políticas públicas. Diferentemente de abordagens que tendem a focar, ora na dimensão das ruas (Bringel; Pleyers, 2015; Alonso; Mische,

17 Outro foco da Marcha das Margaridas é a luta por democracia interna no MSTTR, aspecto não abordado neste trabalho. 
2017; Ortellado; Solano, 2016; Telles, 2016), ora na dos gabinetes (Abers; Serafim; Tatagiba, 2014; Abers; von Bülow, 2011), este estudo faz uma análise conjugada dessas duas formas de ação para compreender melhor o fenômeno das ações coletivas dos movimentos sociais (Teixeira, 2018).

O protesto de rua é um dos momentos mais emblemáticos da atuação da Marcha das Margaridas, devido à grande visibilidade pública que atinge. Em 2000 e em 2003, a Marcha durava um dia. A partir de 2007, passou a acontecer em dois dias. O primeiro dia é dedicado ao acolhimento das participantes, ou seja, à recepção das mulheres no momento de chegada à Brasília, à realização de atividades formativas, como seminários, oficinas, debates, painéis e rodas de conversas, à exposição e troca de produtos e sementes feitos pelas participantes, à abertura política da Marcha e a atividades culturais. Neste dia, as ações de reprodução social e as formas de ação coletiva se sobrepõem. Além disso, pelo menos nas duas últimas mobilizações, as Margaridas utilizaram este primeiro dia para aderir a outros protestos que aconteciam na cidade. Em 2019, em uma das reuniões de organização da Marcha, as coordenadoras nacionais e estaduais avaliavam a importância da representação das Margaridas nestes atos, uma vez que as pautas englobam temáticas convergentes com as agendas política das Margaridas e reforçam $\underset{\widetilde{~}}{ }$ as resistências contra as novas direitas. ${ }^{18}$ Não กิ é incomum também que no primeiro dia algumas ativistas participem de reuniões com agentes do Estado, aproveitando a presença na $\neg$ capital federal para encontrar e negociar com $\therefore$ agentes estatais, fato elucidativo sobre como ঙं as formas de ação coletiva se inter-relacionam

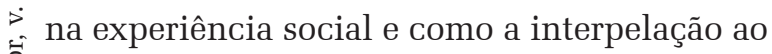
Estado não acontece somente nos momentos mais comumente estudados, como em mesas

If ${ }^{18}$ Em 2015, participaram de um ato conjunto em defesa

da manutenção dos royalties de petróleo para a educação.

Em 2019, aderiram ao Dia Nacional de Mobilizações, Pa-

ralisações e Greves Contra a Reforma e Contra os Cortes

na Educação e ao protesto de rua da Marcha das Mulheres Indígenas. de negociações e espaços participativos, mas também em situações menos visíveis e mais cotidianas da política.

As aberturas políticas da Marcha costumam ser longas, chegando a cerca de três horas de duração, porque as organizadoras da Marcha procuram incluir a fala dos principais representantes envolvidos na construção da mobilização, apoiadores e personalidades políticas. ${ }^{19}$ É um espaço de visibilidade pública pelo qual há certa concorrência. O cálculo político sobre quem fala (e quem não fala) envolve muitas negociações entre as coordenadoras da Marcha. Esta definição é parte importante da construção de alianças políticas, portanto, também dimensão de reprodução social. Em 2015, o ex-presidente Luiz Inácio Lula da Silva e ministros do governo Dilma estiveram na abertura, evidência da interlocução estabelecida entre a Marcha e o governo. Este cenário mudou em 2019, quando não houve a presença de nenhum ministro do governo em exercício, mostrando uma mudança substantiva da relação entre a Marcha e agentes do poder executivo do Estado, mais uma expressão de como se desenvolve a relação entre Estado e movimentos sociais. Esta transformação se expressou também de outras formas, como por meio da não negociação de pauta com o poder executivo, como mostrarei a seguir.

O segundo dia da Marcha é dedicado ao protesto nas ruas. As ativistas acordam cedo. Muitas relatam que sequer dormem devido à ansiedade pelo dia seguinte e pela excitação de estar cercada por companheiras com quem podem trocar experiências e confraternizar. O percurso e a distribuição das delegações regionais ao longo da marcha são planejados previamente.

A decisão sobre a ordem de apresentação dos eixos e qual delegação se encarregaria de cada um deles tem como finalidade demonstrar qual é a mensagem que as ativistas transmitem nas ruas - quais temas são apresentados primeiro e qual região se responsabiliza por

${ }^{19}$ A abertura política foi seguida e/ou intercalada por atividades culturais em ambos os anos. 
cada eixo temático. Em 2015, o primeiro eixo temático da marcha foi "democracia, poder e participação”, o que denota a eleição, feita pelas coordenadoras da Marcha, da centralidade do debate naquele momento. Nas atividades de preparação da Marcha, ouvi de diferentes pessoas envolvidas com a organização que uma das preocupações daquele momento era como realizar as denúncias e protestar contra as políticas do executivo nacional que não concordavam, como o forte ajuste econômico realizado na época, sem acelerar a crise política que ameaçava a presidenta de impeachment, pela qual a Marcha se posicionou contrária. Essa preocupação era particularmente importante considerando que um protesto anti-Dilma estava agendado para quatro dias após a Marcha das Margaridas (Manifestações..., 2015). Dessa forma, a ação das Margaridas acabou sendo interpretada na mídia como o protesto que polarizaria com o dos ativistas contra o governo, mesmo estando agendada há mais de um ano. Esse fato levou a Marcha a ser interpretada como a "Marcha da Resistência (ao golpe, às crises, às tensões, às dificuldades econômicas" (Moreira, 2019, p. 63). Diante deste cenário, muitas organizações começaram a procurar a organização da Marcha para aderir à mobilização. Para lidar com a demanda conjuntural às vésperas do protesto, a coordenação divulgou uma carta intitulada "Margaridas demarcam posição frente à atual conjuntura política nacional e combatem qualquer tipo de desrespeito, intolerância, incitação ao ódio e violência contra as mulheres", na qual se posicionava em relação à conjuntura e pela qual expressava suas posições políticas. Embora a interpretação de que se vivia um momento de ameaças democráticas apontasse para um cenário de restrições políticas, por outro lado essas ameaças se tornaram uma oportunidade de ampliar a mobilização e alianças. A carta divulgada procurava ampliar mobilização e alianças garantindo uma unidade política e programática da Marcha.

Em 2019, acompanhei um dos debates sobre como distribuir a ordem de saída das delegações e os eixos temáticos conforme cada região. A decisão da comissão organizadora foi ter à frente da Marcha a delegação do Nordeste, a maior de todas. ${ }^{20}$ Em seguida, as do Norte e Sudeste. Finalmente, as representantes do Centro-Oeste e Sul. A decisão de ter as ativistas nordestinas no começo do protesto não foi apenas pelo seu tamanho, mas porque consideraram a importância de dar visibilidade política às mulheres daquela região, onde Bolsonaro obteve seu pior resultado eleitoral no segundo turno das eleições $2018^{21}$ e que tem sido alvo de críticas e frases racistas do presidente. ${ }^{22}$ Portanto, semanas antes da Marcha, o Nordeste era alvo dos ataques de Bolsonaro e as lideranças da Marcha interpretaram esta situação como uma oportunidade política para dar visibilidade às nordestinas no enfrentamento ao político. Os dois eixos temáticos escolhidos para estar à frente da Marcha em 2019 foram: "por terra, água e agroecologia", relativo consenso entre a comissão organizadora, e "por uma vida livre de todas as formas de violência, sem racismo e sem sexismo", que foi escolhido por se considerar que retratava mais diretamente das questões vivenciadas pelas mulheres naquele momento. O outro eixo que se considerou trazer para a frente da mobilização foi "por democracia com igualdade e fortalecimento da participação política das mulheres", tema também considerado central pelas lideranças, mas que acabou não sendo priorizado na comparação com o que se queria evidenciar inicialmente, o tema da violência.

A marcha acontece na Esplanada dos Ministérios, longa avenida da capital federal ${ }^{20}$ É no Nordeste que se encontra o maior número de estabelecimentos da agricultura familiar - 47,2\% do total nacional (IBGE, 2019).

${ }^{21}$ Bolsonaro teve $30,3 \%$ dos votos válidos, contra 69,7\% do outro candidato, Fernando Haddad (PT). Disponível em: https:/g1.globo.com/politica/eleicoes/2018/eleicao-em-numeros/noticia/2018/10/29/haddad-ganha-no-nordeste-e-bolsonaro-nas-demais-regioes-do-pais.ghtml. Acesso em 10 abr. 2021.

${ }^{22}$ Em 19 de julho de 2020, Bolsonaro se referiu aos governadores do Nordeste como "governadores de paraíba" (Bolsonaro..., 2020). Poucos dias depois, em 22 de julho de 2020 , o presidente voltou a causar polêmica com fala preconceituosa na qual fez piada com o tamanho da cabeça das pessoas dessa região (Bolsonaro..., 2019). 
Brasília, na qual se encontram os prédios da administração pública federal, sobretudo os ministérios. Ao final da avenida, está a praça dos Três Poderes, onde se localiza a sede dos poderes legislativo, executivo e judiciário. Em ambas as Marchas, o destino final foi o prédio do Congresso Nacional. Uma vez lá, um carro de som é estacionado, e uma série de discursos políticos de representantes da Marcha, movimentos sociais e políticos se sucedem até que o público se disperse. Mais do que marchar, o protesto de rua das Margaridas envolve atos políticos com focos específicos, eleitos a partir dos objetivos identificados na agenda política construída previamente, e com base na análise das oportunidades políticas.

Em 2015, o foco do ato político foi o Congresso Nacional, uma vez que um dos principais objetivos da Marcha naquele ano era protestar contra potenciais retrocessos democráticos que poderiam ser causados pela abertura de impeachment contra a presidenta. Naquele momento, cabia ao então presidente da Câmara dos Deputados aceitar, ou não, o pedido de abertura do processo de impeachment. Além disso, outro ato político aconteceu no estádio de futebol Mané Garrincha, local de acampamento das Margaridas, quando a presidenta Rousseff encontrou as ativistas da Marcha para responder a pauta de reivindicação. Este ato era menos um momento de protesto e mais de interlocução entre a Marcha e o poder $\overrightarrow{\tilde{~}}$ executivo. O conflito não era o marcador prinऽิ cipal desta relação, como foi no ato no Congresso, mas a interlocução.

Em 2019, os focos dos atos foram os Ministérios da Agricultura, do Meio Ambiente, ¿. da Economia e da Justiça, áreas consideradas ले centrais como alvos da ação naquele momen-

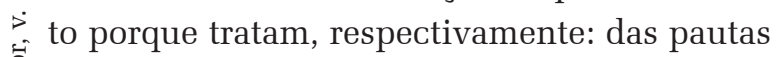
políticas agrícolas que influenciam a vida das mulheres no meio rural; ${ }^{23}$ da intensa destruição do meio ambiente para a qual o Ministro ${ }^{23}$ O Ministério do Desenvolvimento Agrário foi extinto em 2016, ainda no governo Temer (2016-2017). Por isso, deixou de ser um dos focos de protesto da Marcha. Muitas das suas responsabilidades passaram para o Ministério da Agricultura. do Meio Ambiente tem sido negligente e cúmplice $^{24}$; do debate da Reforma da Previdência, em tramitação naquela ocasião; e da pauta da criminalização dos movimentos sociais. Falas políticas nos carros de som e ações de gritos de ordem das ativistas ganhavam intensidade na frente dos alvos dos seus protestos.

Outra forma de ação coletiva da Marcha é a interpelação de agentes do Estado, cujo objetivo principal é demandar políticas públicas e direitos. Esta forma de ação coletiva é consagrada na atuação do MSTTR (Teixeira, 2018). De forma geral, a Marcha cria uma pauta de reivindicações e a entrega com antecedência a representantes do Estado, a fim de iniciar um processo de negociação. Em 2015, a pauta foi entregue para o poder executivo e para o poder legislativo no mês que antecedeu a Marcha. ${ }^{25}$ Este processo culminou com a resposta da presidenta Dilma Rousseff às demandas das Margaridas após a ação de rua. Neste interim, uma série de reuniões com diversos agentes estatais, inclusive ministros e a própria presidenta marcaram o processo de negociação das demandas. Para Alessandra Lunas, um dos significados importantes da Marcha foi colocar as mulheres diretamente em diálogo por seus direitos, sem intermediários falando por elas. ${ }^{26}$ Um documento com 72 páginas foi entregue ao governo federal e, conforme ouvi a coordenadora da Marcha naquele ano relatar algumas vezes, foi bem recebido pelos agentes do Estado, que o consideraram um guia para orientar políticas públicas. Contudo, para a negociação que antecedeu a Marcha, alguns itens foram priorizados, como as políticas e o fomento à produção agrícola por meio da implantação

${ }^{24}$ Falas do Ministro do Meio Ambiente de 22 de abril de 2020 revelaram a intenção do político de aproveitar o foco da atenção pública na pandemia da covid-19 para mudar regras à proteção ambiental e à área de agricultura. (Ministro..., 2020).

${ }^{25}$ Além disso, as coordenadoras da Marcha das Margaridas também elaboraram um documento com propostas estratégicas da Marcha para o Plano Plurianual 2016-2019, que teve o objetivo de estabelecer diálogos a fim de construir proposições mais concretas que beneficiassem as mulheres do campo, da floresta e das águas.

${ }^{26}$ Entrevista com Alessandra Lunas realizada pelo autor em 26 de outubro de 2015. 
dos quintais produtivos, que se tornou uma das principais conquistas da Marcha em 2015 (Maia; Teixeira, 2021). Os quintais produtivos são espaços adjacentes aos domicílios rurais em que as mulheres produzem alimentos, cultivam plantas medicinais, criando pequenos animais e cuidando do meio ambiente, geralmente orientadas por princípios agroecológicos.

Devido ao contexto de 2015, marcado pelo enfraquecimento político do governo, a percepção comum entre muitas das lideranças que participaram das negociações era de que não seria feito nenhum anúncio político de muita relevância, considerando a conjuntura que ameaçava a líder do país. A percepção das coordenadoras era de que o governo temia que qualquer ação pudesse aprofundar a crise econômica e política em curso.

O encontro entre o representante máximo do poder executivo e a coordenadora nacional da Marcha não se repetiu em 2019. A coordenação da mobilização optou por não entregar uma pauta política e estabelecer um processo de negociação com agentes do Estado na sexta mobilização. Ao invés disso, as Margaridas lançaram uma plataforma política, documento que reunia o projeto de sociedade defendido pelas mulheres do campo, da floresta e das águas. Pelo menos duas novidades caracterizam este fato. Primeiramente, a não entrega e negociação de uma pauta a agentes do poder executivo, por entender que a negociação naquele momento significaria dar legitimidade ao governo e atestar uma normalidade democrática em um contexto de fragilização dos princípios e instituições democráticas. Além disso, havia a avaliação da comissão organizadora de que não deviam negociar com um governo cujo discurso se caracteriza pela subjugação das mulheres. Em segundo lugar, a materialização de um documento dirigido a diferentes esferas - sociedade, agentes do Estado e organismos internacionais. Se ao longo da sua história a Marcha procurou dialogar com todas as esferas mencionadas, em 2019 esse foi o foco central da reivindicação das Mar- garidas e se materializou em um documento denominado plataforma política. A plataforma se tornou um documento de denúncia do "desmonte do Estado democrático de direito" (Contag, 2019a, p. 2). Dessa forma, a relação com agentes do Estado, antes marcada por negociações, passou a se caracterizar sobretudo pelo enfrentamento. A maneira de demandar se reconfigura e dinâmicas mais dialógicas, não necessariamente sem conflitos, passam a ser marcadas por práticas contenciosas.

A decisão de não entregar uma pauta ou de estabelecer um processo de negociação com agentes do poder executivo não se deu sem tensões entre os diferentes atores envolvidos na Marcha, sobretudo, no interior do MSTTR. Diferentes interpretações sobre as oportunidades políticas e distintas abordagens sobre como se relacionar com agentes do Estado também permearam outros temas, como em relação ao debate da Reforma da Previdência, proposta pelo presidente Bolsonaro em 2019, e discussão central no debate público no momento da Marcha. Entre vários pontos, a reforma propunha mudanças de regras para a aposentadoria de trabalhadores rurais, alterando idade e tempo mínimo, e alíquotas de contribuição. Enquanto alguns grupos na Contag defendiam cautela e falavam que eram contra alguns pontos da Reforma da Previdência, a Marcha produziu um documento que se posicionou contra a Reforma. Essa diferenciação de posição foi possível porque a Marcha, embora tenha como coordenadora nacional a dirigente sindical da Contag, é organizada com um conjunto de outros movimentos e organizações. A decisão da coordenação ampliada da Marcha de se posicionar contra a Reforma se sustentava, sobretudo, a partir de uma interpretação de que a proposta afetava sobretudo a vida das mulheres. Este episódio é elucidativo sobre como a estratégia de ação de interpelação ao Estado é construída a partir de leituras das oportunidades políticas, que nem sempre são consensuais, mas variam conforme seus diferentes interlocutores, suas posicionalidades, objetivos e alianças.

Em suma, nesta seção, analisei as prin- 
cipais formas de ação coletiva da Marcha das Margaridas em 2015 e 2019: os protestos de rua e a interpelação ao Estado. Mais do que ações estanques, elas estão inter-relacionadas e se complementam, assim como estão permeadas pelas ações de reprodução social - é no processo de construção da Marcha que se mobiliza mais ativistas, que a formação acontece e que novas alianças se forjam. Em particular, a investigação sobre a reconfiguração da relação da Marcha com o governo federal revelou mudanças no padrão de relação, de um foco mais dialógico e marcado por negociações (não necessariamente isenta de conflitos) para uma interpelação conflitiva, marcada pela reivindicação da pauta. Portanto, as Margaridas interpretaram o novo contexto e reorientaram suas ações de acordo com suas leituras políticas, construindo alternativas de resistências às novas direitas sem abandonar a ação nas ruas e nos gabinetes.

\section{CONSIDERAÇÕES FINAIS}

Neste trabalho, analisei como a atuação de movimentos sociais populares foi afetada e reagiu ao contexto político de ascensão das novas direitas por meio do estudo da Marcha das Margaridas em 2015 e 2019. Para isso, utilizei as categorias analíticas, ações de reprodução social e formas de ação coletiva, investigando como elas se reconfiguram de acordo com as interpreনิ tações que os sujeitos políticos fazem das opor- tunidades políticas. Uma das vantagens destes conceitos é ampliar a investigação para além da ¿ face pública dos movimentos sociais, sobretudo, $\stackrel{7}{7}$ os protestos, mas trazer para o centro de investi¿. gação o processo de construção da mobilização लि que se opera no cotidiano e garante não só a pe$\vec{r}$ renidade das mobilizações e movimentos, mas também as próprias ações coletivas.

As ações de reprodução social se reorientaram sobretudo no sentido de ampliação das alianças, seja no âmbito oficial de organização da Marcha, com a chegada de novos atores, seja no campo mais espontâneo, de adesão de su- jeitos políticos ao protesto de rua em um contexto de ameaças de retrocesso democráticos, em 2015, ou já de consolidação das forças da nova direita por meio do governo Bolsonaro, em 2019. Desta forma, as alianças reforçaram e ampliaram também as mobilizações, que precisaram se reinventar no novo contexto, como demonstrei por meio do exemplo da arrecadação de recursos, que pela primeira vez incluiu uma campanha de financiamento coletivo na internet. No plano da formação política, a reorientação ocorreu sobretudo no sentido da eleição de temas antes não centrais, como o debate sobre democracia, que ganha a cena a partir de 2015.

Em relação às formas de ação coletiva, o contexto de ascensão das novas direitas impõe uma nova leitura dos temas centrais da Marcha, que se expressam nos atos de rua: em ambos os anos o tema da democracia ganhou destaque, aspecto que não era o foco nas mobilizações anteriores, e a pauta da violência contra as mulheres e criminalização dos movimentos sociais também adquiriu centralidade. A negociação com agentes do Estado, que marcou a Marcha principalmente desde 2003, deixou de ser feita em 2019, quando as ativistas centraram a ação na comunicação da sua agenda política com setores mais amplos da sociedade, agentes do Estado e organismos internacionais, sem endereçá-la e negociá-la com o governo federal. Se antes a negociação orientava esta relação, em 2019 o poder executivo passou a ser alvo de reivindicações. As ativistas protestavam por suas agendas, não mais estabeleciam um processo de negociação.

Este artigo se diferencia dos demais estudos sobre movimentos sociais e protestos no Brasil nos anos recentes ao menos em três aspectos. Primeiro, analiso uma mobilização social que se caracteriza pela sua perenidade e organicidade, e não pela sua espontaneidade e curto período de existência, característica comum a protestos como os da Jornada de junho de 2013 ou mesmo as mobilizações de 2015 e 2016 a favor e contra o impeachment de Dilma Rousseff e antipetistas. Com isso, lanço 
luzes para a reflexão sobre como movimentos populares mais perenes, atores sociais que há décadas têm lutados por direitos e políticas, têm construído resistências e alternativas às novas direitas. Segundo, investigo como mobilizações sociais mais perenes atuam em diferentes contextos com ameaças e restrições políticas distintas, investigando a capacidade de resposta dos movimentos sociais em diferentes conjunturas, abordagem que não cabe aos estudos de eventos de protestos pontuais. Por fim, me baseio em uma abordagem teórica que busca compreender a atuação dos movimentos sociais para além das suas formas de ação coletiva, como os protestos, enfocando também nas suas ações de reprodução social, quando não há grande visibilidade pública. A análise destas duas dimensões de maneira interdependente é fundamental para compreender como as resistências e alternativas às novas direitas no Brasil estão se realizando e sendo construídas por movimentos sociais populares não só no plano visível das ruas, mas também na dimensão cotidiana da vida política.

Recebido para publicação em 15 de dezembro de 2020 Aceito em 22 de abril de 2021

\section{REFERÊNCIAS}

ABERS, R.; SERAFIM, L.; TATAGIBA, L. Repertórios de interação estado-sociedade em um estado heterogêneo: a experiência na Era Lula. Dados, Rio de Janeiro, v. 57, n. 2, p. 325-357, 2014

ABERS, R.; von BÜLOW, M. Movimentos sociais na teoria e na prática: como estudar o ativismo através da fronteira entre estado e sociedade? Sociologias, Porto Alegre, v. 3 , n. 28, p. 52-84, 2011.

ABRANCHES, S. H. (ed.). Democracia em risco? 22 ensaios sobre o Brasil hoje. São Paulo: Companhia das Letras, 2019.

ABREU, J. M.; ALLEGRETTI, G. Comportamento político violento e avanço global da direita: uma análise do caso brasileiro. Crítica e Sociedade, Uberlândia, v. 6, n. 2, 2016.

AGUIAR, V. V. P. Mulheres rurais, movimento social e participação: reflexões a partir da Marcha das Margaridas. Política \& Sociedade, Florianópolis, v. 15, p. 261-295, 2016.

Somos todas margaridas: um estudo sobre o processo de constituição das mulheres do campo e da floresta como sujeito político. 2015. Tese (Doutorado em Ciências Sociais) - Universidade Estadual de Campinas, 2015.
ALCÂNTARA, L. M. Ciberativismo e movimentos sociais: mapeando discussões. Aurora, São Paulo, v. 8, n. 23, p. 73$97,2015$.

ALMEIDA, R. Bolsonaro presidente: conservadorismo, Evangelismo e a crise brasileira. Novos estudos CEBRAP, São Paulo, v. 38, n. 1, p. 185-213, 2019.

ALONSO, A.; MISCHE, A. Changing Repertoires and Partisan Ambivalence in the New Brazilian Protests. Bulletin of Latin American Research, Hoboken, v. 36, n. 2, p. 144-159, 2017.

ALONSO, A. A política das ruas. Novos estudos CEBRAP, São Paulo, v. 37, n. 1, p. 49-58, 2017.

BOLSONARO faz piada contra nordestinos sobre tamanho da cabeça. Bnews, Salvador, 22 jul. 2019. Disponível em: https://www.bnews.com.br/noticias/politica/ politica/241252,bolsonaro-faz-piada-contra-nordestinossobre-tamanho-da-cabeca.html. Acesso em: 10 abr. 2021

BOLSONARO ataca nordestinos: "Daqueles governadores de 'paraíba', o pior é do Maranhão”. G1, Rio de Janeiro, 2020. Disponível em: https://g1.globo.com/globonews/ jornal-das-dez/video/bolsonaro-ataca-nordestinosdaqueles-governadores-de-paraiba-o-pior-e-o-domaranhao-7779504.ghtml. Acesso em: 10 abr. 2021

BOULOS acredita que frente ampla de centro-esquerda deterá o fascismo de Bolsonaro. Correio do Brasil, Rio de Janeiro, 18 mar. 2020. Disponível em: https://www. correiodobrasil.com.br/boulos-acredita-que-frente-amplade-centro-esquerda-detera-o-fascismo-de-bolsonaro. Acesso em: 9 abr. 2021.

BRINGEL, B.; PLEYERS, G. Junho de 2013... Dois anos depois: polarização, impactos e reconfiguração do ativismo no Brasil. Nueva Sociedad, Buenos Aires, nov. 2015.

BRINGEL, B. Bolsonaro y el fin del ciclo democrático en Brasil. In: MUGGENTHALER, F; HOETMER, R.; AGUIRRE, M. (org.). Nuevas derechas autoritarias. Quito: AbyaYala/Fundación Rosa Luxemburg, 2020. p. 149-174.

CARVALHO, P. D. Controvérsias e a produção do transnacional: os casos da Contag e do MPA. Dados, Rio de Janeiro, v. 64, n. 2, 2021

CONTAG. Política Nacional de Formação - PNF. Brasília, DF: Contag. 2008

. Marcha das Margaridas 2019. Margaridas na luta por um Brasil com Soberania popular, democracia, justica, igualdade e livre de violência. Cartilha de divulgaçã̃o. Brasília, DF: Contag, 2019b.

. Plataforma Política Marcha das Margaridas 2019. Por um Brasil com soberania popular, democracia, justica, igualdade e livre de violência. Brasília, DF: Contag, 2019a. FEDERICI, S. Calibã e a bruxa: mulheres, corpo e acumulação primitiva. São Paulo: Elefante, 2004.

GOMES, S. A cultura como alternativa: uma aproximacão a partir de sociabilidades militantes na Zona Oeste do Rio de Janeiro. Dilemas, Rio de Janeiro, v. 13, n. 1, p. 57-76, 2020 .

HONNETH, A. Luta por reconhecimento: a gramática moral dos conflitos sociais. São Paulo: 34, 2003.

HORA, K.; MACEDO, G.; REZENDE, M. (org.). Coletânea sobre estudos rurais e gênero: Prêmio Margarida Alves $4^{\text {a }}$ Edição. Brasília, DF: Ministério do Desenvolvimento Agrário, 2015.

IBGE. Censo agropecuário 2017: resultados definitivos. Rio de Janeiro: IBGE, 2019.

JOÃO Pedro Stédile: "Nós temos que retomar o trabalho de base”. Pt.org.br, São Paulo, 29 out. 2018. Disponível em: https://pt.org.br/joao-pedro-stedile-nos-temos-queretomar-o-trabalho-de-base. Acesso em: $11 \mathrm{dez} .2020$. 
LONGO, I. Bolsonaro atiça seguidores contra o MST e termo "terroristas" vai para o topo do Twitter. Revista Fórum, São Paulo, 5 out. 2020. Disponível em: https://revistaforum. com.br/redes-sociais/bolsonaro-atica-seguidores-contra-omst-e-termo-terroristas-vai-para-o-topo-do-twitter. Acesso em: 9 dez. 2020.

LUIZ, J. R.; CARVALHO, P. D.; TEIXEIRA, M. A. CrossMovement in Latin America: lessons from the Mercosur Confederation of Family Farming Organisations (Coprofam). Moving the Social, Bochum, v. 63, p. 41-63, 2020 .

MAIA, A. B.; TEIXEIRA, M. A. Food movements, agrifood systems, and social change at the level of the national state: the Brazilian Marcha das Margaridas. The Sociological Review, Thousand Oaks, p. 1-21, 2021.

MANIFESTACÕES Anti-Dilma voltam às ruas do Brasil. El País, Madri, 19 ago. 2015. Disponível em: $\quad$ https://brasil.elpais.com/brasil/2015/08/16/ politica/1439728675 375038.html. Acesso em: 9 abr. 2021.

McADAM, D. Political process and the development of black insurgency. Chicago: University of Chicago Press, 1999

McCARTHY, J. D.; ZALD, M. N. Resource mobilization and social movements: a partial theory. American Journal of Sociology, Chicago, v. 82, n. 6, 1977.

MEDEIROS, L. S.; NEVES, D. P. (org.). Mulheres Camponesas: trabalho produtivo e engajamento político. Niterói: Alternativa, v. 1, 2013.

MEDEIROS, L. S. Movimentos sociais no governo Bolsonaro. Revista da ANPEGE, Dourados, v. 16, n. 29, p. 484-515, 2020.

MELUCCI, A. A invenção do presente: movimentos sociais nas sociedades complexas. Petrópolis: Vozes, 2001.

MIGUEL, L. F. Jornalismo, polarização política e a querela das fakenews. Estudos de Jornalismo e Mídia, Florianópolis, v. 16 , p. 46-58, 2019a.

. Por que Bolsonaro não cai. Revista IHU On-line. São Leopoldo, 2019b. Disponível em: http://www.ihu. unisinos.br/78-noticias/594038-por-que-bolsonaro-naocai-artigo-de-luis-felipe-miguel. Acesso em: 1 jun. 2021.

MINISTRO do meio ambiente defende passar a "boiada" e "mudar" regras enquanto atenção da mídia está voltada para a Covid-19. G1, Rio de Janeiro, 22 maio 2020. Disponível em: https://g1.globo.com/politica/noticia/2020/05/22/ ministro-do-meio-ambiente-defende-passar-a-boiada-emudar-regramento-e-simplificar-normas.ghtml. Acesso em: 10 abr. 2021.

亏ิ MOREIRA, S. L. S. A contribuição da Marcha das N Margaridas na construcão das políticas públicas de œ agroecologia no Brasil. Dissertação (Mestrado em Meio - Ambiente e Desenvolvimento Rural) - Universidade de N Brasília, DF, 2019.

- MOTTA, R.; TEIXEIRA, M. A. Allowing rural difference to $\checkmark$ make a difference: the Brazilian Marcha das Margaridas. - In: CONWAY, J.; DUFOR, P; MASSON, D. (ed.). Cross$\therefore$ Border solidarities in twenty-first century contexts: feminist fi perspectives and activist practices. Lanham, Maryland: \% Rowman and Littlefield, 2021.

\& ORTELLADO, P.; SOLANO, E. Nova direita nas ruas? Uma análise do descompasso entre manifestantes e os \pm convocantes dos protestos antigoverno de 2015. Perseu: कึ História, Memória e Política, São Paulo, v. 11, 169-180, 2016.

İ PALMEIRA, M. Desmobilização e conflito: relações entre trabalhadores e patrões na agroindústria pernambucana. In: FERNANDES, B. M., MEDEIROS, L. S., PAULILO, M. I. (org.). Lutas camponesas contemporâneas: condições, dilemas e conquistas. O campesinato como sujeito ङ político nas décadas de 1950 a 1980. São Paulo: Editora
Unesp; Brasília, DF: Núcleo de Estudos Agrários e Desenvolvimento Rural, 2009. v. 1, p. 171-200.

SILVA, F. P. Quinze anos da onda rosa latino-americana: balanço e perspectivas. Observador On-Line, Rio de Janeiro, v. 9, n. 12, 2014

PETRARCA, F. R. Carwash operation and the complex mechanism of political corruption in Brazil. Civitas, Porto Alegre, v. 20, n. 3, p. 425-438, 2020.

PIMENTA, S. D. Experiências em trajetórias de mulheres rurais: engajamento sindical, feminismos e subjetividades. 2019. Tese (Doutorado em Psicologia) - Universidade Federal de Minas Gerais, Belo Horizonte, 2019.

PINHEIRO-MACHADO, R. Amanhã Vai Ser Maior: o que aconteceu com o Brasil e as possíveis rotas de fuga para a crise atual. São Paulo: Planeta do Brasil. 2019.

ROSSI, F. Conceptualizing strategy making in a historical and collective perspective. In: ROSSI, F; von BÜLOW, M. (ed.). Social movement dynamics: new perspectives on theory and research from Latin America. Londres: Routledge, 2016. p. 15-42.

SANTOS, F.; TANSCHEIT, T. Quando velhos atores saem de cena: a ascensão da nova direita política no Brasil. Colombia internacional, n. 99, p. 151-186, 2019.

SCOTT, J. C. Formas cotidianas de resistência camponesa. Raízes, Campina Grande, v. 21, nº 1, p. 10-31, 2002.

SIGAUD, L. A luta de classes em dois atos: notas sobre um ciclo de greves camponesas. Dados, Rio de Janeiro, v. 29, 1986.

SILVA, M. K. De volta aos movimentos sociais? Reflexões a partir da literatura brasileira recente. Revista Ciências Sociais Unisinos, São Leopoldo, v. 46, p. 2-9, 2010.

SINGER, A. Brasil, junho de 2013, classes e ideologias cruzadas. Novos estudos CEBRAP, São Paulo, n. 97, p. 2340, 2013.

SOLANO, E. A bolsonarização do Brasil. In: ABRANCHES, S. H. (ed.), Democracia em risco? 22 ensaios sobre o Brasil hoje. São Paulo: Companhia das Letras, 2019.

SOLANO, E. et al. (ed.). O ódio como política: a reinvenção das direitas no Brasil. São Paulo: Boitempo, 2018.

TARROW, S. O poder em movimento: movimentos sociais e confronto político. Petrópolis: Vozes, 2009.

TATAGIBA, L.; GALVÃO, A. Os protestos no Brasil em tempos de crise (2011-2016). Opinião Pública, Campinas, v. 25 , n. 1 , p. $63-96,2019$.

TEIXEIRA, M. A. Formas de ação coletiva: reflexões a partir dos conflitos por terra em Magé, RJ. Política \& Sociedade, Florianópolis, v. 14, n. 30, p. 27-55, 2015.

TEIXEIRA, M. A. S. Movimentos sociais, ações coletivas e reproducão social: a experiência da Contag (1963-2015). 2018. 2018. Tese (Doutorado em Sociologia)-Universidade do Estado do Rio de Janeiro, Rio de Janeiro, 2018.

TEIXEIRA, M. A.; MOTTA, R. M. Unionism and feminism: alliance building in the Brazilian Marcha das Margaridas. Social Movement Studies, Berlim, p. 1-17, 2020.

TELLES, H. A direita vai às ruas: o antipetismo, a corrupção e democracia nos protestos antigoverno. Ponto-e-Vírgula: Revista de Ciências Sociais, São Paulo, n. 19, 2016.

THOMPSON, E. P. Costumes em comum: estudos sobre a cultura popular e tradicional. São Paulo: Companhia das Letras, 1998.

TILLY, C. From mobilization to revolution. Nova York: Random House, 1978.

TOURAINE, A. O retorno do ator - ensaio sobre sociologia. Lisboa: Instituto Piaget, 1984. 
SOCIAL MOVEMENTS IN TIMES OF THE RISE OF THE NEW RIGHT: the Marcha das Margaridas

\author{
Marco Antonio Teixeira
}

This article analyses the Marcha das Margaridas, a feminist mobilisation spearheaded by women from the Brazilian Union of Rural Workers in alliance with other social movements, trade unions, and international organisations in the years 2015 and 2019 - considered to be the time of the rise of the new right. From a theoretical approach that regard the performance of social movements based on the concepts of actions of social reproduction and forms of collective action, we analyse the Marcha beyond its most visible expression - that is, a large street protest in the city of Brasilia, and the negotiations with state agents (forms of collective action). Rather, we understand this movement as also involving a long process of organisation, mobilisation, political formation activities, and politics of alliances with other social actors (actions of social reproduction). By analysing them interdependently and vis-à-vis the political opportunity structures at the time of the rise of the new right, we will better understand how social movements acted considering the new context.

Keywords: Social Movements. New Rights. Collective Actions. Social Reproduction Actions. Marcha das Margaridas.

\section{LES MOUVEMENTS SOCIAUX POPULAIRES FACE A LA MONTEE DE LA NOUVELLE DROITE: la Marcha das Margaridas}

Marco Antonio Teixeira

Larticle analyse la Marcha dasMargaridas, une mobilisation féministe qui a eu lieu au Brésil entre 2015 et 2019, période considéré comme celle de la montée de la nouvelle droite brésilienne. Dirigée par des femmes qui se réclament défenseuses de la campagne, des forêts et des eaux, la Marcha était organisée par des femmes du Mouvement Syndical des Travailleuses et Travailleurs Ruraux, en alliance avec d'autres mouvements sociaux, des centrales syndicales et des organisations internationales. L'approche théorique propose une analyse à partir du concept de "actions de reproduction sociale" et de "répertoires d'action collective". Cela signifie qu'il faut analyser la Marcha au-delà de son expression la plus visible, à savoir, une grande marche à Brasília accompagnée des négociations avec les agents de l'État (répertoire d'action collective). La Marcha implique également un long processus d'organisation, de rassemblement, de formation et des politiques d'alliances avec d'autres acteurs sociaux (actions de reproduction sociale). Analyser ces éléments de manière interdépendante en fonction de la structure des opportunités politiques, et dans la période de montée de la nouvelle droite brésilienne, nous aide à mieux comprendre comment les mouvements sociaux populaires ont agi dans ce nouveau contexte.

Mots-ClÉs: Mouvements Sociaux. Nouvelle Droite. Repertoires D'action Collectives. Actions De Reproduction Sociale. Marcha Dasmargaridas. 
